\title{
An online community-based dynamic customisation model: the trade-off between customer satisfaction and enterprise profit
}

\author{
Wang, Yu; Wu, Jiacong; Lin, Li; Shafiee, Sara
}

Published in:

International Journal of Production Research

Link to article, DOI:

10.1080/00207543.2019.1693649

Publication date:

2021

Document Version

Peer reviewed version

Link back to DTU Orbit

Citation (APA):

Wang, Y., Wu, J., Lin, L., \& Shafiee, S. (2021). An online community-based dynamic customisation model: the trade-off between customer satisfaction and enterprise profit. International Journal of Production Research, 59(1), 1-29. https://doi.org/10.1080/00207543.2019.1693649

\section{General rights}

Copyright and moral rights for the publications made accessible in the public portal are retained by the authors and/or other copyright owners and it is a condition of accessing publications that users recognise and abide by the legal requirements associated with these rights.

- Users may download and print one copy of any publication from the public portal for the purpose of private study or research.

- You may not further distribute the material or use it for any profit-making activity or commercial gain

- You may freely distribute the URL identifying the publication in the public portal 


\title{
An Online Community-based Dynamic Customisation Model: The Trade-off
}

\section{Between Customer Satisfaction and Enterprise Profit}

\author{
Yu Wang ${ }^{a, c}$, Jiacong Wu $u^{b, c^{*}}$, Li Lin ${ }^{b, c}$, Sara Shafiee ${ }^{d}$ \\ a School of International Business, Jinan University (Zhuhai Campus), Zhuhai, 519070, China; \\ twygs@jnu.edu.cn (Y.W.) \\ ${ }^{\mathrm{b}}$ School of Management, Jinan University, Guangzhou, 510632, China \\ skywu@stu2017.jnu.edu.cn (J.W.); li1258085120@163.com (L.L.) \\ ${ }^{c}$ Institute of Management Science and Engineering, Jinan University (Zhuhai Campus), Zhuhai, 519070, \\ China \\ ${ }^{d}$ Department of Mechanical Engineering, Technical University of Denmark, Kgs. Lyngby, 2800, Denmark; \\ sashaf@mek.dtu.dk (S.S.) \\ *Correspondence: skywu@stu2017.jnu.edu.cn (J.W.); sashaf@mek.dtu.dk (S.S.).
}

\begin{abstract}
In recent years, the challenges of mass customisation (MC) have been increasing sales conversion rate and effectively matching supply with demand. Additionally, online customer communities (OCCs) have become increasingly popular and have proven to provide substantial value to both customers and enterprises. Therefore, the focus of this paper is to (1) propose a mathematical online community-based dynamic customisation model, (2) explain its practical mechanism and (3) solve its dynamic trade-off challenge. Accordingly, first, the trade-off challenge was formulated according to a multi-objective optimisation model to optimise the trade-off between customer satisfaction and enterprise profit. Second, based on the mechanism of the model, three different matching modes of production between customised products and manufacturers were delineated and analysed. Finally, genetic algorithm (GA) was developed to solve the proposed mathematical model. To validate the proposed model, a case study of an enterprise that provides customised menswear was selected. The degree of customisation and the weights given to the functions of enterprise profit and customer satisfaction were further analysed. The proposed model assists researchers and practitioners to decide the cooperation mode with manufacturers, pricing strategy and the degree of customisation for an optimal trade-off in the context of online community-based dynamic customisation.
\end{abstract}

Keywords: online customer community (OCC); mass customisation (MC); dynamic trade-off; multiobjective optimisation; genetic algorithm (GA) 


\section{Introduction}

Undoubtedly, as the heterogeneity of customer demand increases, mass customisation (MC) is becoming an important driver of innovative business models, especially in e-commerce (Gownder 2011). MC will have to generate value other than the provision of cost-saving measures to both customers and producers to become a viable business strategy. Many customers prefer MC because of its low-cost, high-volume and efficient production of personalised products that meets the requirements of their orders (Felfernig et al. 2014). Producers benefit from MC by being able to offer personalised products at higher prices while retaining loyal and satisfied customers (Zhou et al. 2013). However, in reporting the benefits of $\mathrm{MC}$, several prominent enterprises were unable to demonstrate significant revenue streams via MC (Piller et al. 2014). Within the last five years, a small number of enterprises have invested considerably in the development of online customisation. Still, even after investing substantial capital into the system and toolkits of $\mathrm{MC}$, these enterprises have faced the challenges of low sales conversion rate. This low sales conversion rate is due in part to the number of customers choosing customisation options being far fewer than expected (Hvam et al. 2008; Shafiee et al. 2017).

Previous researchers have offered several suggestions for improving the $\mathrm{MC}$ process. One option is offering useful MC toolkits to customers, who can thereby address their personalisation needs with personalised information technology (IT)-based product configurations (Blazek and Kolb 2012; Schnurr and Scholl-Grissemann 2015; Wei et al. 2014; Zhang 2014). Other options include product modularity (Daaboul and Cunha 2014; Shaik et al. 2015; Viana et al. 2017), product configuration (Hvam et al. 2012; Yang et al. 2012) or product family design (Bonev et al. 2015; Galizia et al. 2019; Hsiao et al. 2013; Jung and Simpson 2016), all of which are effective ways to reduce the complexity of MC. Finally, optimal methods of production planning can be designed to match flexible production requirements to time-varying customer demand (Mleczko and Bobiński 2017; Nielsen et al. 2014; Ramadan et al. 2016; Zhong et al. 2013, 2015). Moreover, decision support systems have been introduced to guide industrial companies and practitioners during the design and selection of efficient product platforms, managing the trade-off between platforms variety and required platforms customisation effort (Galizia et al. 2019). However, the effectiveness of these methods in increasing the sales conversion rate of $\mathrm{MC}$ will be limited to the number of customers who actually choose customisation. Lack of customer freedom in product configuration or high customisation prices could still deter customers (Fettermann and Echeveste 2014).

The emphasis on manufacturing has shifted from a manufacturer-dominating to a customercentric manner by actively involving users into the co-creation process to realise individual satisfaction (Zheng et al. 2019). Co-creation is defined as an active, creative and social collaborative process between users and manufacturer, aiming at creating values for customers (Piller et al. 2010). Cocreation can open up a brand to the outside world and help it to generate relevant innovations. Moreover, online customer communities (OCCs) have become increasingly popular and shown a high potential to drive co-creation (Romero and Molina 2011). Accordingly, OCCs was described as an online network of individuals who engage in social interactions to share their enthusiasm for specific 
brands, their user experience or feedback on the products, retail environments, and consumption activities (Manchanda et al. 2015).

Therefore, both academics and practitioners have investigated other feasible methods for addressing the challenges of MC above via OCCs (Blazek and Kolb 2012; Straßburger 2013). Manchanda et al. (2015) described the potential economic benefits of OCCs as 'social dollars', believing that customers who join an OCC become more engaged with firms and/or their products. Several recent studies have also presented evidence that OCCs provide substantial value to enterprises. Additionally, OCCs have made it easier for customers to submit their ideas and become part of the cocreation process (Blazek and Kolb 2012; Fombelle et al. 2016; Piller et al. 2012). Both Dell and Starbucks are well known for their continuous efforts to create a large community through which thousands of new products and service ideas have been generated (Bayus 2013; Luo and Toubia 2015). OCCs have also been proven to enhance brand loyalty of customers (Laroche et al. 2012; Pai and Tsai 2011). Moreover, OCCs can be used to reduce uncertainty about the performance of customer's selfdesigned products and to largely replace costly customer service (Blazek and Kolb 2012). Moreover, OCCs help facilitate customer aggregation, which is important in MC (Liu et al. 2011; Shang et al. 2013). Therefore, this paper aims to describe how enterprises that provide customised products/services take advantage of OCCs to increase sales conversion rates and effectively match demand with supply.

In recent decades, $\mathrm{MC}$ and OCCs have received increasing attention from academics and practitioners, but the studies that have combined MC and OCC remain scarce. Scholars have mainly conducted this research from the customer perspective (Ind et al. 2013), focusing on customer motivations (e.g., Fuller 2010), resources (e.g., Gummesson and Mele 2010), and experiences (e.g., Ramaswamy and Gouillart 2010; Srai et al. 2016; Zheng et al. 2019). Several studies have focused on how to mine and discover the co-created knowledge gained from OCCs to support product innovation (Dong and Wu 2015; Jaakkola and Alexander 2014; Jing et al. 2015; Wu et al. 2013). However, to the best of authors' knowledge, these studies have seldom focused on how to cluster and manage customer requirements through OCCs to effectively match demand with supply. Previous studies have also lacked the practical guidance and methodology necessary to indicate ways for enterprises that provide customised products/services to increase sales conversion rates. Additionally, most prior research has focused merely on the theoretical value of OCCs for MC, including increases in customisation productivity, customers' engagement in product innovation and brand loyalty. Although these studies have pointed out that OCCs are the future trend of MC, they have provided little practical value for enterprises and practitioners (Blazek and Kolb 2012; Fombelle et al. 2016; Laroche et al. 2012; Manchanda et al. 2015; Straßburger 2013; Wang et al. 2012). Academics and practitioners still lack a visual model to explain the concrete realisation mechanism whereby OCCs can be combined with MC to match demand with supply. Mathematical derivation analysis conducted according to the real-world circumstances of enterprises that provide customised products/services has also been scarce in previous research. To fill this research gap, the impact of OCCs on customer aggregation must first be 
assessed. Additionally, determining the matching mode among OCCs, customised products and manufacturers is an urgent challenge that must be investigated. In this paper, to make a precise contribution in the context of community economy, mathematical modelling techniques were used to calculate the trade-off between enterprise profit and customer satisfaction.

This paper contributes to the production research literature from different perspectives and encompasses a variety of audiences with different interests and needs, ranging from researchers, to corporate practitioners that manufacture customised products/services and also consultants. Contribution of this research and its relevance to different audiences can be summarised in the following five paragraphs.

First, the paper builds on the concept of online community-based customisation and proposes a theoretical model to clearly explain its concrete realisation mechanism. The research expands the state of art on MC and OCCs by combining MC with OCCs to overcome MC's challenges of increasing sales conversion rate and effectively matching supply with demand. Based on the previous literature regarding the potential theoretical benefits of OCCs for MC, a visual theoretical model is further proposed to clearly explain how they can be combined to overcome the challenges of MC for researchers. The process of customer aggregation, the match modes among OCCs, customised products and manufacturers, and the advantages of each cooperation mode with manufactures are explained in detail in the proposed theoretical model.

Second, the paper constructs a novel mathematical model for leveraging enterprise profit with customer satisfaction in order to achieve dynamic trade-off. Dynamic in this case means that our proposed online community-based customisation model captures and analyses customer data constantly and in real time. In the context of OCCs, the constraints of customers and enterprises under different matching modes were considered in the model to assist enterprises during decision making. The proposed model supports: first the practitioners and enterprises that provide customised products/services; second, the consultants regarding decisions about the cooperation mode with manufactures and pricing strategy for an optimal trade-off between enterprise profit and customer satisfaction in the context of online community-based customisation; and third, the researchers to gain a better understanding regarding the constraints and trade-off of online community-based customisation.

Third, Genetic Algorithm (GA) was chosen to prove the practical application of this model. Three types of customisation scenarios are further considered for better decision support in the future decision making process of enterprises. The proposed model provides managers with further insights if they should maintain the degree of the present customisation, conduct additive customisation strategy or use subtractive customisation strategy. Enterprises can decide on optimal customisation strategies according to their current operation state and their future business model benefiting from this proposed model.

Fourth, this paper further analysed the sensitivity of the weights of the enterprise-profit function and the customer-satisfaction function to study the uncertainty in the output of the mathematical model. 
The further sensitivity analysis provides researchers and practitioners with insights about the impact of management preferences for enterprise profit and customer satisfaction.

Finally, in order to check the robustness of the results and evaluate the effectiveness of the GA, a novel algorithm known as firefly algorithm (FA) was chosen to solve the proposed model. The robustness checks further convince researchers and practitioners about the feasibility of the proposed model, and the results and conclusions attained from the case study.

The rest of this paper is organised as follows: The next section describes relevant studies already conducted in this research area. Section 3 proposes a theoretical model to explain the realisation mechanism of online community-based customisation. Section 4 presents the problem statement in detail and formulates it as a multi-objective optimisation model. Genetic algorithm (GA) with matrix encoding has been designed to solve the mathematical programming model in Section 5. Section 6 uses a case study from a customised menswear enterprise to validate the proposed model and algorithm. Finally, implications of the findings and future directions are discussed.

\section{Literature Review}

In recent years, efforts have been made to meet personalised customer demand and involve customers in product innovation while improving the operation of customisation. Accordingly, both $\mathrm{MC}$ and OCCs have attracted growing research attention. Three streams of literature relevant to this research are described below and in three sections. The first section of the literature focuses on the studied methods for improving the performance of MC. The second section studies the research available on the impact of OCCs on customers and enterprises. The third section of the literature review discusses the optimisation of production allocation based on the constrains. Finally, the discussed literature from all three sections is summarized in Table 2.

\subsection{Existing methods for improving the performance of $M C$}

Methods for improving the performance of MC are identified in order to review the status quo of MC and establish a foundation for the method proposed in this paper. Salvador et al. (2009) proposed a conceptual framework comprising three capabilities - solution space development, robust process design and choice navigation — of a successful MC firm. Piller et al. (2014) tested this framework empirically and examined its effect on firm performance. Viana et al. (2017) illustrated how modularity can reduce the complexity of MC. Mourtzis et al. (2015) carried out a multi-criteria decision-making procedure for evaluating the quality of alternative manufacturing network configurations. Bonev et al. (2015) developed a generic modelling method called the integrated-design model (IDM) to create a consistent formal approach for the design and customisation of entire product families. Zhong et al. (2013) presented an Radio-frequency identification (RFID)-enabled real-time manufacturing execution system to track and trace manufacturing objects and collect real-time production data in MC production. Nielsen et al. (2014) developed a constraint-programming-based methodology to satisfy on-time customer demand. Hao et al. (2017) proposed the application of an automatic virtual metrology system together with a target-value adjustment scheme to meet the 
requirements of MC production. Sheng and Khamidi (2018) presented a fresh approach to MC, including design option visualisation, digital product information and $n$-dimensional modelling, to spearhead much-needed change in the industry. Galizia et al. (2019) proposed a decision support system to guide industrial companies and practitioners in the design and selection of efficient product platforms. There are many specific works related to tools that aim to optimise product design and configuration process as Gu et al. (2009), Shafiee et al. (2017), Summers and Shah (2010). The review from Zennaro et al. (2019) reveals several trends over time such as the role of the customer has received more attention, or the factors affecting customisation and complexity of production. Ameri et al. (2008) focused on customisation complexity, in terms of products and production, while Shafiee et al. (2017) analysed the scoping of product configuration systems in ETO environments. Additionally, studies about uncertainty factors in terms of costs and time are widely diffused (Grabenstetter and Usher, 2013).

\subsection{The impact of OCCs on customers and enterprises}

Co-creation is the joint, collaborative, concurrent, peer-like process of producing new value, both materially and symbolically (Gummesson et al. 2014). There is an ongoing debate in the literature about the differences between co-creation and co-production and the need to distinguish between them (Gronroos and Voima 2013). In recent years, OCCs have been popular aiming at involving consumers in enterprises' development processes (Gebauer et al. 2013), and OCCs have shown a high potential to drive co-creation (Romero and Molina 2011). Customers come together in OCCs to share their experiences with products and services, and give feedback (Romero and Molina 2011). They may provide useful suggestions and ideas, nice comments, and collective commitment on new products or services (Gebauer et al. 2013). The importance of the impact of OCCs on customers and enterprises has been analysed. This section highlights the main roles that OCCs play in MC and attempts to determine whether OCCs can be combined with MC to improve MC performance. Fombelle et al. (2016) identified the types of consumers who provide enterprises with ideas regarding how to improve their offerings in OCCs, which has become an increasingly popular research trend. Straßburger (2013) found that OCCs could serve as a lever for MC productivity. Blazek and Kolb (2012) showed that OCCs added value to the shopping experience and to the customisation process, as well as reduced uncertainty about the performance of the customer's own design. Laroche et al. (2012) and Pai and Tsai (2011) demonstrated and explained how and why OCCs enhance brand loyalty among customers. Wang et al. (2012) confirmed that OCCs have a positive influence on customers' purchase intentions, while customers' need for uniqueness was noted as exhibiting a moderating effect. Liu et al. (2011) and Shang et al. (2013) suggested that OCCs play an important role in customer aggregation, such that the value of the 'long tail' effect should be fully mined. Other perspectives to be considered when delineating the co-creation field's boundaries in management-related theories are those of innovation studies (Chesbrough 2003, 2006), which focus on collaborative and open processes involving companies and users. 


\subsection{The constraints for optimising production allocation}

Finally, the literature discusses the optimisation of production allocation to determine which constraints need to be considered. The methods to optimise production allocation when OCCs are combined with MC to improve the performance of MC is also addressed. Liang et al. (2004) proposed a linear programming model that quantifies customer demand and enterprise output to solve the problem of production allocation in MC. Tang et al. (2012) presented a multi-objective model of production allocation in $\mathrm{MC}$, which includes enterprise profit and degree of customer satisfaction. Yao (2013) developed a dynamic and multi-objective optimisation model, as well as an algorithm to schedule the optimisation of co-operator selection and task allocation in MC. Bao et al. (2014) constructed a bi-level mathematical programming model of optimal resource allocation in product customisation. Cheng et al. (2015) used intuitional fuzzy theory to construct a production allocation model that considers existing production-capacity constraints in MC. Bao et al. (2016) constructed a multi-objective optimisation model of task allocation in product customisation and solved it based on another model of double-population-adaptive GA. In sum, previous research has addressed two types of constraints. The constraints for optimising production allocation are summarised in Table 1 .

Table 1. The constraints for optimising production allocation

\begin{tabular}{|c|c|c|c|c|c|c|c|c|c|}
\hline \multicolumn{2}{|c|}{ Constraints } & \multirow{2}{*}{$\begin{array}{c}\text { Liang } \\
\text { et al. } \\
(2004) \\
\sqrt{ }\end{array}$} & \multirow{2}{*}{$\begin{array}{c}\text { Zhou } \\
\text { et al. } \\
(2004) \\
\sqrt{ }\end{array}$} & \multirow{2}{*}{$\begin{array}{l}\text { Zhou } \\
\text { et al. } \\
(2007)\end{array}$} & \multirow{2}{*}{$\begin{array}{c}\text { Liang } \\
\text { et al. } \\
(2009) \\
\sqrt{ }\end{array}$} & \multirow{2}{*}{$\begin{array}{c}\text { Tang et } \\
\text { al. } \\
(2012) \\
\sqrt{ }\end{array}$} & \multirow{2}{*}{$\begin{array}{c}\text { Bao et } \\
\text { al. } \\
(2014)\end{array}$} & \multirow{2}{*}{$\begin{array}{c}\text { Cheng } \\
\text { et al. } \\
(2015) \\
\sqrt{ }\end{array}$} & \multirow{2}{*}{$\begin{array}{c}\text { This } \\
\text { paper } \\
\qquad \sqrt{ }\end{array}$} \\
\hline \multirow{5}{*}{$\begin{array}{l}\text { Customer } \\
\text { satisfaction }\end{array}$} & $\begin{array}{l}\text { Attribute } \\
\text { deviation degree }\end{array}$ & & & & & & & & \\
\hline & $\begin{array}{l}\text { Utility and cost } \\
\text { of customers }\end{array}$ & & & $\sqrt{ }$ & & & & & \\
\hline & Price & & & & $\sqrt{ }$ & $\sqrt{ }$ & $\sqrt{ }$ & & $\sqrt{ }$ \\
\hline & Delivery date & & & & & & $\sqrt{ }$ & & $\sqrt{ }$ \\
\hline & Quality & & & & & & $\sqrt{ }$ & & \\
\hline \multirow{7}{*}{$\begin{array}{c}\text { Enterprise } \\
\text { profit }\end{array}$} & $\begin{array}{l}\text { Utility and cost } \\
\text { of manufacturers }\end{array}$ & & & $\sqrt{ }$ & & & & & \\
\hline & Sales revenue & & & & & $\sqrt{ }$ & $\sqrt{ }$ & $\sqrt{ }$ & $\sqrt{ }$ \\
\hline & Production costs & & & & & $\sqrt{ }$ & $\sqrt{ }$ & $\sqrt{ }$ & $\sqrt{ }$ \\
\hline & Collaboration & & & & & $\sqrt{ }$ & $\sqrt{ }$ & & $\sqrt{ }$ \\
\hline & costs & & & & & & & & \\
\hline & Labour costs & & & & & & $\sqrt{ }$ & & $\sqrt{ }$ \\
\hline & Logistics costs & & & & & & $\sqrt{ }$ & & $\sqrt{ }$ \\
\hline
\end{tabular}


Moreover, several recent studies have also proposed few models to support enterprises for supplier selection from the sustainability and risk mitigation perspectives (Azadnia et al. 2015; Yoon et al. 2018; Zimmer et al. 2016). However, as the urgent challenges of MC include increasing sales conversion rate and effectively matching supply with demand, enterprises need to satisfy customers while maintaining a certain profit to survive in the market first. Therefore, the constraints of sustainability and risk mitigation are not considered in the model at this time.

\subsection{Summary of the literature on MC}

Table 2 summarises the available literature on MC relevant to the current research, including methods for improving the performance of $\mathrm{MC}$, the impact of OCCs on customers and enterprises, the optimisation of production allocation and the identified constraints.

Table 2. Summary of the literature on MC

\begin{tabular}{|c|c|c|}
\hline Literature on MC & References & Summary \\
\hline $\begin{array}{l}\text { Methods for } \\
\text { improving the } \\
\text { performance of MC }\end{array}$ & $\begin{array}{l}\text { Salvador et al. (2009); } \\
\text { Piller et al. (2014); } \\
\text { Viana et al. (2017); } \\
\text { Mourtzis et al. (2015); } \\
\text { Bonev et al. (2015); } \\
\text { Zhong et al. (2013); } \\
\text { Nielsen et al. (2014); } \\
\text { Hao et al. (2017); } \\
\text { Sheng et al. (2018); } \\
\text { Galizia et al. (2019); } \\
\text { Gu et al. (2009); } \\
\text { Shafiee et al. (2017); } \\
\text { Summers et al. (2010); } \\
\text { Zennaro et al. (2019); } \\
\text { Ameri et al. (2008); } \\
\text { Grabenstetter et al. (2013) }\end{array}$ & $\begin{array}{l}\text { Many studies of MC have sought to determine the methods needed to improve } \\
\text { the performance of MC from several angles, including providing MC toolkits } \\
\text { for easy-to-operate customisation, using product modularity, product } \\
\text { configuration, product family design or efficient product platforms design and } \\
\text { selection to simplify MC and developing optimal methods of production } \\
\text { planning to match demand and supply in real time. However, these studies } \\
\text { have seldom focused on the low sales conversion rate of MC, which is a } \\
\text { serious problem recently faced by most enterprises that provide customised } \\
\text { products/services. Thus, this paper attempts to address this problem from a } \\
\text { unique angle. }\end{array}$ \\
\hline $\begin{array}{l}\text { The impact of OCCs } \\
\text { on customers and } \\
\text { enterprises }\end{array}$ & $\begin{array}{l}\text { Gummesson et al. (2014); } \\
\text { Gronroos et al. (2013); } \\
\text { Gebauer et al. (2013); } \\
\text { Romero et al. (2011); } \\
\text { Fombelle et al. (2016); } \\
\text { Straßburger (2013); } \\
\text { Blazek et al. (2012); } \\
\text { Laroche et al. (2012); } \\
\text { Pai and Tsai (2011); }\end{array}$ & $\begin{array}{l}\text { In recent years, co-creation and OCCs have received increasing attention from } \\
\text { academics and practitioners. Most studies have shown the positive impact of } \\
\text { OCCs on customers and enterprises in several respects, including providing } \\
\text { customers with an opportunity for product co-creation, enhancing brand } \\
\text { loyalty, increasing customers' purchase intentions and aggregating similar } \\
\text { customers. These studies have provided strong support, especially regarding } \\
\text { the impact of customer aggregation, for further research on the combination } \\
\text { of OCCs and MC to increase the sales conversion rate of MC. Therefore, this } \\
\text { paper proposes a theoretical model to explain the realised mechanism of }\end{array}$ \\
\hline
\end{tabular}




\begin{tabular}{|c|c|c|}
\hline & $\begin{array}{l}\text { Wang et al. (2012); } \\
\text { Liu et al. (2011); } \\
\text { Shang et al. (2013); } \\
\text { Chesbrough }(2003,2006)\end{array}$ & online community-based customisation, which few studies have examined. \\
\hline $\begin{array}{l}\text { The constraints for } \\
\text { optimising production } \\
\text { allocation }\end{array}$ & $\begin{array}{l}\text { Liang et al. (2004); } \\
\text { Zhou et al. (2004); } \\
\text { Zhou et al. (2007); } \\
\text { Tang et al. (2012); } \\
\text { Yao et al. (2013); } \\
\text { Bao et al. (2014); } \\
\text { Cheng et al. (2015); } \\
\text { Bao et al. (2016); } \\
\text { Azadnia et al. (2015); } \\
\text { Yoon et al. (2018); } \\
\text { Zimmer et al. (2016) }\end{array}$ & $\begin{array}{l}\text { The optimisation of production allocation in MC is not a novel issue; } \\
\text { numerous studies have been devoted to the issue over many years. These } \\
\text { studies have mainly focused on how to construct a multi-objective } \\
\text { optimisation model that considers the degree of customer satisfaction and } \\
\text { enterprise profit to solve the problem of production allocation under MC. Two } \\
\text { types of constraints, including customers' and enterprises', were mainly } \\
\text { considered in the optimisation models. However, the studies largely } \\
\text { constructed their multi-objective optimisation models in the context of MC } \\
\text { rather than with regard to online community-based customisation. } \\
\text { Accordingly, this paper focuses on solving the urgent problems of MC with a } \\
\text { multi-objective optimisation model that better fits the context of online } \\
\text { community-based customisation. }\end{array}$ \\
\hline
\end{tabular}




\section{The Proposed Theoretical Model for Online Community-based Dynamic Customisation}

As stated in the previous sections, to solve the problem of low sales conversion rate in $\mathrm{MC}$, this study combines OCCs with MC. A theoretical online community-based dynamic customisation model is proposed here to explain the concrete realisation mechanism of online community-based customisation. First, this model illustrates the dynamic matching mode among OCCs, customised products and manufacturers, as shown in Figure 1.

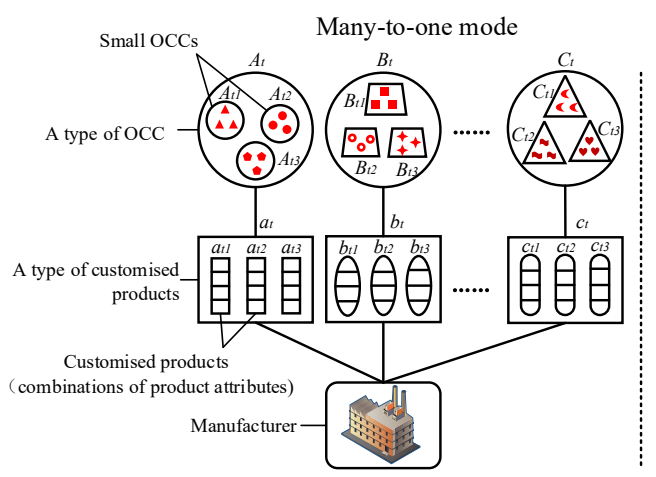

(a)

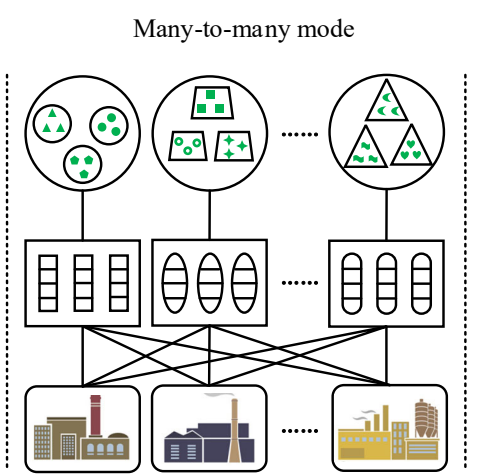

(b)

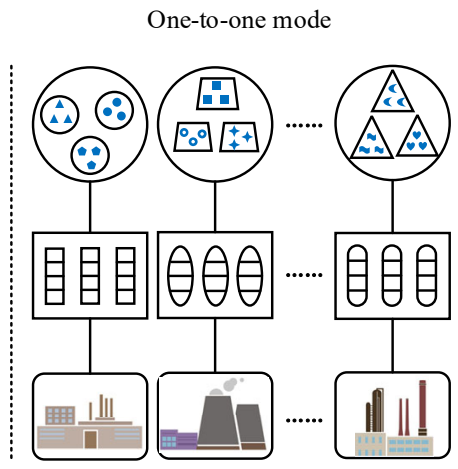

(c)

Figure 1. Online community-based dynamic customisation model.

Based on the fact that the demand of customers changes over time and constantly. In different time periods, customers aggregated into different OCCs. Then, OCCs are matched with different customized products and accordingly customized products may need to be matched to manufacturers in different ways. Therefore, our proposed online community-based dynamic customization model catches and analyses the data of customers in each period of time as real-time data. So our model can match the customized products and manufacturers and as a consequence optimize the pricing portfolio in each time period.

First, similar customers are dynamically aggregated into an OCC. Based on the strong aggregation impact of OCCs (Shang et al. 2013), customers with similar customised demand are more likely to identify each other and aggregate into a small OCC in each time period ( $t$ ) (e.g., $A_{t 1}, A_{t 2} \ldots A_{t i}, B_{t 1}$, $B_{t 2} \ldots B_{t i}, C_{t 1}, C_{t 2} \ldots C_{t i}$, and so on). Similar small OCCs further aggregate into a type of OCC in each time period $(t)$ (e.g., $A_{t 1}, A_{t 2} \ldots A_{t i}$ aggregate into type $A_{t}$ OCC; $B_{t 1}, B_{t 2} \ldots B_{t i}$ aggregate into type $B_{t}$ OCC; $C_{t 1}, C_{t 2} \ldots C_{t i}$ aggregate into type $C_{t}$ OCC, etc.). The dynamic aggregation of customers can be identified by social network analysis at each time period. However, the proposed theoretical model only considers the mechanism of customer aggregation and not how customer aggregation works in actual practice. This paper focuses on how to match the mode of customised products to the mode of manufacturing, as well as the optimal pricing portfolio, hypothesising that dynamic customer aggregation will be successful.

Second, OCCs are dynamically matched with customised products. As customers aggregate into different OCCs in different time periods, similar customised demand in each OCC will change dynamically. Therefore, the matched customised products for each OCC are adjusted according to the 
dynamic customised demand. In each time period $(t)$, each small OCC is matched with a customised product (e.g., $A_{t 1}$ matches $a_{t 1}, A_{t 2}$ matches $a_{t 2}, A_{t i}$ matches $a_{t i}, B_{t i}$ matches $b_{t i}, C_{t i}$ matches $c_{t i}$, etc.). Akin to small OCC aggregation, similar customised products are aggregated into types of customised products (e.g., customised product $a_{t 1}, a_{t 2} \ldots a_{t i}$ aggregate into type $a_{t}$ customised products, customised product $b_{t 1}, b_{t 2} \ldots b_{t i}$ aggregate into type $b_{t}$ customised products, customised product $c_{t 1}, c_{t 2} \ldots c_{t i}$ aggregate into type $c_{t}$ customised products, etc.). Accordingly, each type of OCC matches a corresponding type of customised product (e.g., type $A_{t}$ OCC matches type $a_{t}$ customised products; type $B_{t}$ OCC matches type $b_{t}$ customised products; type $C_{t}$ OCC matches type $c_{t}$ customised products, etc.).

Finally, customised products are dynamically matched to manufacturers in each time period $(t)$. As customised products can be described as being made up of a combination of many different customised product components, the matching modes can be divided into three types:

(1) Many-to-one mode: To reduce transaction costs spread among different manufacturers, various types of customised products are instead produced by a single manufacturer (as shown in Fig. 1(a), type $a_{t}, b_{t}$ and $c_{t}$ customised products match the same manufacturer).

(2) Many-to-many mode: Each manufacturer has the advantage of producing specific kinds of product attributes. To benefit from these advantages, each type of customised product is produced by various manufacturers together. Each manufacturer only produces what works to its advantage (the kinds of product attributes that they specialise in), and the final products are assembled by every product attribute produced by these manufacturers, as shown in Figure 1(b).

(3) One-to-one mode: In each type of customised product category, the products are similar. Therefore, this mode does not significantly increase production costs; however, it can reduce transaction costs compared to the many-to many mode, as shown in Figure 1(c).

Given the illustration of the dynamic-matching mode between OCCs, customised products and manufacturers complete, focus can now be placed on how to choose the optimal matching mode and determine the optimal pricing portfolio. Based on the literature of production allocation in $\mathrm{MC}$, as shown in Table 1, two types of constraints are considered to solve the challenge of the dynamic tradeoff of online community-based customisation: (1) the constraint of customers, which can be described as customer satisfaction, such as delivery date, price and the degree of customisation (attributedeviation degree); (2) the constraint of enterprises, which can be described as enterprise profit, including sales revenue from products, collaboration costs, labour costs and logistics costs. Additionally, as this model is an online community-based customisation model, the operational costs of the community are also considered. 


\section{Mathematical Multi-Objective Optimisation Model of Online Community-based Dynamic}

Customisation

This section first describes the assumptions of the proposed problem in detail. Sections 4.2 and 4.3 develop the profit function of the enterprise that provides customised products and the satisfaction function of online communities, respectively. The mathematical multi-objective optimisation model of the dynamic trade-off is established, and all mentioned variables are summarised in section 4.4.

\subsection{The statement of the problem}

Based on the theoretical model proposed in Section 3, a multi-objective optimisation mathematical model was established to resolve the challenge of the dynamic trade-off of online community-based customisation. This paper uses GA (based on the criteria in Section 5) to optimise the pricing portfolio of customised products and the matching mode with manufacturers in order to maximise the combination of customer satisfaction and enterprise profit. The constraints of customers and the enterprise under different matching modes were considered in the construction of the model. Further, this paper adjusts the degree of customisation after determining the optimal matching mode with manufacturers, thus providing effective advice regarding customisation strategies for the future development of enterprises that provide customised products.

To simplify the process of proposing the model, some assumptions were made:

(1) The degree of customisation was divided into two types: the number of designable attributes and the number of selectable attributes. The number of designable attributes is the number of customisable attributes of the product, while the number of selectable attributes can be interpreted as the number of selectable styles for each designable attribute. Taking menswear as an example, the designable attributes include the collar, cuffs and buttons, and the selection attributes include the styles of collar, the styles of cuffs and the styles of buttons.

(2) The online community platform was divided into $n$ communities based on the number of designable attributes, which means that each community corresponds to a customised product with a different number of designable attributes. In addition, the maximum number of designable attributes that can be customised by the enterprise is $r_{\text {max }}$.

(3) As customers in the same community have similar demand, this study assumed that they would also have the same satisfaction level with the customised products.

(4) The fixed cost of plant and OCC construction was not included. The cost of raw materials, design, manufacturing, etc., were all included in the production cost.

(5) The cost of community operation was assumed to be directly proportional to the number of products purchased by customers.

(6) This study assumed that a truck would be available to load goods for two communities, and the distance between manufacturers, suppliers and the enterprise was assumed to be the same $(1 \mathrm{~km})$.

(7) The weight of each community's satisfaction was determined based on its sales volume, which is regarded as the demand from each community. 


\subsection{Profit of the enterprise that provides customised products}

The revenue of an enterprise that provides customised products mainly comes from the sale revenues of its customised products. Therefore, the revenue of an enterprise is equal to the demand for its products multiplied by the price of the products. Based on the constraints discussed in Table 1, in this paper, costs include collaboration costs relating to value chains, community operation costs relating to the enterprise and labour costs. Therefore, the enterprise profit of the $i^{t h}$ community can be presented as follows:

$$
Q_{i}=P_{i} q_{i}-C_{a i}-C_{b i}-C_{e}
$$

where $Q_{i}$ is the total customised product profit of the $i^{\text {th }}$ community for the enterprise, $P_{i}$ is the price of the customised products in the $i^{\text {th }}$ community, $C_{a i}$ represents the collaboration costs between the enterprise and its partners for the production of the $i^{\text {th }}$ community's customised products, $C_{b i}$ are the operational costs of the $i^{t h}$ community and $C_{e}$ are the labour costs, which are determined by the enterprise itself.

\section{(1) Demand of customised products}

Demand for a customised product is negatively affected by higher prices and longer committed delivery dates. Referring to both the literature (Narenji et al. 2013) and the actual case discussed in this paper, the demand function of customised products is as follows:

$$
q_{i}=\gamma_{i}-\beta_{1} P_{i}-\beta_{2} T_{i}\left(\gamma_{i}, \beta_{1}, \beta_{2}>0\right)
$$

where $\gamma_{i}$ is the maximum demand when both the price of a customised product and its committed delivery date are 0 in the $i^{\text {th }}$ community. $\beta_{1}$ and $\beta_{2}$, respectively, represent the sensitivity coefficient of price and the committed delivery date. $T_{i}$ is the committed delivery date without considering the potential for late delivery.

\section{(2) Collaboration cost}

With the assumption that fixed costs are not taken into consideration, collaboration costs include the investment in cooperative production and the logistics costs within the value chain (Chen et al. 2004). Thus, the equation of collaboration costs is as follows:

$$
C_{a i}=C_{c i}+C_{d i}
$$

where $C_{c i}$ is the investment in cooperative production, which means the committed production costs between the enterprise and its partners. $C_{d i}$ represents the logistics costs within the value chain. $C_{c i}$ and $C_{d i}$ are calculated in the following subsections.

\section{1) Investment in cooperative production}

The production cost of customised products are twofold: the production cost of common attributes and the production cost of customised attributes. The cost of common attributes is the same for all products and is denoted by $v$. The cost of customised attributes is positively correlated with the 
number of customised attributes, and the variable cost of each customised attribute is $u$. The equation for $C_{c i}$ is based on Dewan et al. (2003):

$$
C_{c i}=\left(u \times r_{i}^{2}+v\right) \times q_{i}
$$

where $r_{i}$ represents the degree of customisation in the $i^{\text {th }}$ community.

However, there are three matching modes of production (i.e., many-to-one, many-to-many, oneto-one) between customised products and manufacturers. The production costs obviously differ across matching modes. In the many-to-one mode, the enterprise only collaborates with one manufacturer; therefore, this manufacturer must be capable of meeting diversified demand and investing considerably in making products according to various degrees of customisation. Thus, the variable cost of each customised attribute is higher than those of other two matching modes. Accordingly, based on equation (4), $\xi$ (larger than 1) was set as a cost-regulatory factor representing the increased variable cost of each customised attribute in the many-to-one mode. In the many-to-many mode, the manufacturer only needs to process a specific attribute of a customised product, regardless of which community the product belongs to. This means that for a single manufacturer, the degree of customisation of each customised product is 1 . Therefore, in the many-to-many mode, the variable cost of each customised product can be regarded as the sum of the processing cost of each manufacturer participating in production. In the one-to-one mode, the total cost of a customised product in different communities is the same as in equation (4), because each manufacturer only produces one product for one community. In sum, the final formulae of the capital investment in cooperative production are as follows:

$$
C_{c i}=\left\{\begin{array}{l}
\left(\xi \times u \times r_{i}^{2}+v\right) \times q_{i} \\
{\left[u \times k_{i} \times\left(\frac{r_{i}}{k_{i}}\right)^{2}+v\right] \times q_{i}} \\
\left(u \times r_{i}^{2}+v\right) \times q_{i}
\end{array}\right.
$$

where equation (5) to (7), respectively, represent the capital investment in production with the manyto-one, many-to-many and one-to-one modes; $k_{i}$ represents the number of manufacturers cooperating to produce the customised products for the $i^{\text {th }}$ community.

\section{2) Logistics costs}

The costs most commonly understood as the logistics costs are typically transportation and inventory-related costs (Ostlund 1930).

Transportation costs consist of the enterprise's internal and external transportation costs (Weber 2002), while costs related to inventory include warehousing costs and inventory-keeping costs (Hälinen 2015). Warehousing costs can be considered a fixed cost of renting a warehouse while inventory-keeping costs are correlated with the volume of inventory (Lambert 1994). In the online community-based dynamic customisation model presented in this paper, the amount of production is assumed to be equal to demand. Thus, inventory costs in this paper can be specified as 0 . The composition of the logistics costs is therefore presented as follows: 


$$
C_{d i}=C_{d a i}+C_{d b i}+C_{d c i}
$$

where $C_{d a i}$ represents the enterprise's internal transportation costs, $C_{d b i}$ represents its external transportation costs and $C_{d c i}$ corresponds to its warehousing costs.

The enterprise's internal transportation entails goods transportation from one warehouse to another. Thus, this cost is related to truck transportation cost per kilometre and total mileage, as follows:

$$
C_{d a i}=\theta \times \mu_{i}
$$

where $\theta$ is the transportation cost of trucks per kilometre, and $\mu_{i}$ is the total mileage of truck transport for the $i^{\text {th }}$ community.

The external transportation cost is, in this paper, the cost of cooperating with a logistics enterprise to transport products from manufacturers to customers. As the mode of transport is on-demand transportation, the logistics enterprise charges according to the number of products. Thus, the external transportation cost can be denoted by the following equation:

$$
C_{d b i}=\varnothing \times q_{i}
$$

where $\varnothing$ is the average postage for each customised product.

\section{(3) Operational costs}

Considering the assumptions outlined above, the operational costs $\left(C_{b i}\right)$ of the $i^{\text {th }}$ community are directly proportional to the demand for the product $\left(q_{i}\right)$. Thus, the relationship between $C_{b i}$ and $q_{i}$ is as follows:

$$
C_{b i}=\alpha \times q_{i}
$$

\section{(4) Total profit of the enterprise}

The total profit of the enterprise equals the sum of the profits of each community. Furthermore, to normalise the profit to ensure it is in the range of 0 to 1 , the profits of each community are divided by the maximum of total profit $\left(\sum_{i=1}^{n}\left(P_{\max } \times \gamma_{i}\right)\right)$. Thus, the normalised profit of the $i^{\text {th }}$ community $\left(Q_{i}{ }^{\prime}\right)$ and the function of the total profit of the enterprise $(Q)$, are as follows:

$$
\begin{gathered}
Q_{i}^{\prime}=\frac{Q_{i}}{\sum_{i=1}^{n}\left(P_{\max } \times \gamma_{i}\right)} \\
Q=\sum_{i=1}^{n} Q_{i}{ }^{\prime}
\end{gathered}
$$

\subsection{Satisfaction of online communities}

Enterprises should not ignore the importance of customer satisfaction with products in favour of profit, as high customer satisfaction is correlated with an enterprise's long-term survival. Customer satisfaction refers to the differences between perceived quality and cognitive quality (Sun 2008). Based on prior research, in this study customer satisfaction has been divided into three dimensions: customer satisfaction with the delivery date $\left(S_{t i}\right)$, customer satisfaction with the price of products $\left(S_{p i}\right)$, and customer satisfaction with the degree of customisation $\left(S_{d i}\right)$ (Xia 2009). Therefore, the total 
satisfaction $\left(S_{i}\right)$ of the $i^{\text {th }}$ community can be presented as follows:

$$
S_{i}=\omega_{1} \times S_{t i}+\omega_{2} \times S_{p i}+\omega_{3} \times S_{d i}
$$

where $\omega_{1}, \omega_{2}$ and $\omega_{3}$ are the satisfaction weights of the three dimensions. The following section discusses the functions of these three dimensions.

\section{(1) Satisfaction with delivery date}

Due to the special nature of production in $\mathrm{MC}$, the delivery dates of customised products are generally longer than those of non-customised products. Customers might therefore pay more attention to the committed delivery dates, which in turn may affect the degree of customer satisfaction. However, customers are not given an exact delivery date, but rather a period of time. Thus, based on the relevant references (Fang et al. 2006; Li et al. 2013; Santos and Harland 2012), the function of community satisfaction with delivery date is as follows:

$$
S_{t i}=\frac{T_{\max }-T_{i}}{T_{\max }-T_{\min }} \quad\left(T_{\min } \leq T_{i} \leq T_{\max }\right)
$$

where $T_{i}$ is the actual delivery date.

\section{(2) Satisfaction with price}

Based on previous literature, the relationship between customer satisfaction and product price is shown as a curve tilting to the right and convex to the origin. (Fang et al. 2006; Li et al. 2013; Santos and Harland 2012). Assuming the product price set by the enterprise for the $i^{\text {th }}$ community is represented as $P_{i}$, customer satisfaction with price in the $i^{\text {th }}$ community can be expressed as follows:

$$
S_{p i}=\frac{1}{e^{10^{-4} \beta_{1} P_{i}}}
$$

where $\beta_{1}$ represents the price-sensitive coefficient.

\section{(3) Satisfaction with the degree of customisation}

For every customised product, there is a unique factor that affects customer satisfaction, which is the degree of customisation (Cheng et al. 2015). Because of the production capacity of the enterprise, the differences in customer awareness and the expression of their individual requirements, some deviation between the final customised product and the customer's expectation will exist. In this paper, the degree of customer satisfaction is represented by the deviation between the customer's expectation for the customised product and the actual delivered product. Usually, customers tolerate this deviation, and the tolerance restriction is defined as the customers' 'maximum tolerability' $\left(d_{i}\right)$ (Sun and Feng 2013). That is, the deviation between a customer's order and the actual output can be accepted within the range of $d_{i}$, but not otherwise. Thus, the function of the satisfaction with the degree of customisation is as follows:

$$
S_{d i}=1-\left(\frac{R_{i}-r_{i}}{d_{i}}\right)^{3}
$$


where $R_{i}$ represents customers' expected degree of product customisation, and $r_{i}$ is the actual degree of product customisation.

\section{(4) Total satisfaction of communities}

An enterprise can classify customers into different communities, use different strategies for each community, calibrate prices accordingly and, finally, obtain maximum profit. Therefore, it should be noted that enterprises view some communities as more important than others when it comes to customer satisfaction. The importance of each community's satisfaction as related to the total satisfaction of the communities should be measured by different weights. The weight of community satisfaction is positively correlated with product demand from a given community. Thus, the function of the total satisfaction of the communities is as follows:

$$
S=\sum_{i=1}^{n} \frac{q_{i}}{\sum_{i=1}^{n} q_{i}} \times S_{i}
$$

\subsection{Multi-objective optimisation mathematical model of dynamic trade-off}

The purpose of the online community-based dynamic customisation model is to optimise the trade-off between the constraints of the enterprise and customers on a case-by-case basis in real time. Therefore, the objective of the model is to maximise the combination of enterprise profit and community satisfaction $(F)$. Based on the enterprise profit function and the community satisfaction function, a multi-objective optimisation mathematical model of online community-based dynamic customisation can be outlined as follows:

\section{Objective:}

$$
\max F=a \times Q+b \times S
$$

Subject to:

$$
\begin{gathered}
q_{\min } \leq \sum_{i=1}^{n} q_{i} \leq q_{\max } \\
0 \leq r_{i} \leq r_{i+1} \leq r_{\max } \\
\frac{C_{a i}+C_{b i}+C_{e}}{q_{i}} \leq P_{i} \leq P_{i+1} \leq P_{\max }, i=1,2,3, \ldots, n \\
0 \leq \sum_{i=1}^{n}\left(C_{a i}+C_{b i}+C_{e}\right) \leq C_{\max } \\
T_{\min } \leq T_{i} \leq T_{i+1} \leq T_{\max } \\
P_{i}>0, i=1,2,3, \ldots, n
\end{gathered}
$$

where the objective equation (19) is set to maximise the combination of enterprise profit and community satisfaction. $a$ and $b$ are the weights of the enterprise profit function and customer satisfaction function, respectively, and the relationship between them follows the constraint that $a+$ $b=1$. Constraint equation (20) represents the constraint of the production capacity of the enterprise, with $q_{\max }$ and $q_{\min }$ representing the maximum production capacity and minimum production volume, respectively. Constraint (21) expresses the constraint of the degree of customisation (where the minimum of 0 can be interpreted as not customised, and the maximum corresponds to the maximum number of product attributes that can be produced by the enterprise). In addition, based on additional 
customisations, the degree of customisation of the $(i+1)^{t h}$ community should not be less than that of the $i^{t h}$ community. Constraint (22) explains that the price of the customised product cannot be higher than the highest price that customers are willing to pay nor lower than the production cost of the product. Constraint (23) demonstrates the financial constraints of the enterprise, whereby the production costs and operational costs of communities cannot exceed the maximum acceptable investment of the enterprise, $C_{\max }$. Constraint (24) states that the products should be delivered to customers within a period of time no longer than that for which they are willing to wait, but also no shorter than the time needed to produce and deliver the product.

Furthermore, to help readers understand the proposed mathematical model more readily, all variables mentioned above are summarised, as follows, in Table 3. 
Table 3. Summary of variables

\begin{tabular}{|c|c|}
\hline Variables & Description \\
\hline$Q_{i}$ & Total profit of the $i^{\text {th }}$ community \\
\hline$P_{i}$ & Price of the customised products in the $i^{t h}$ community \\
\hline$C_{a i}$ & Collaboration costs of the $i^{\text {th }}$ community's customised products \\
\hline$C_{b i}$ & Operational costs of the $i^{\text {th }}$ community \\
\hline$C_{e}$ & Labour costs \\
\hline$\gamma_{i}$ & Maximum demand of customised products \\
\hline$\beta_{1}$ & Sensitivity coefficient of price \\
\hline$\beta_{2}$ & Sensitivity coefficient of the committed delivery date \\
\hline$T_{i}$ & Committed delivery date \\
\hline$C_{c i}$ & Investment in cooperative production \\
\hline$C_{d i}$ & Logistics costs within the value chain \\
\hline$u$ & Variable cost of each customised attribute \\
\hline$v$ & Costs of common attributes \\
\hline$\xi$ & Cost-regulatory factor of $u$ \\
\hline$k_{i}$ & Number of manufacturers cooperating to produce the products for the $i^{\text {th }}$ community \\
\hline$C_{d a i}$ & Internal transportation costs \\
\hline$C_{d b i}$ & External transportation costs \\
\hline$C_{d c i}$ & Warehousing costs \\
\hline$\theta$ & Transportation costs of trucks per kilometre \\
\hline$\mu_{i}$ & Total mileage for truck transport for the $i^{\text {th }}$ community \\
\hline$\varnothing$ & Average postage for each customised product \\
\hline$Q_{i}{ }^{\prime}$ & Normalised profit of the $i^{t h}$ community \\
\hline$Q$ & Total profit of the enterprise \\
\hline$h$ & Profit function adjustment factor \\
\hline$S_{i}$ & Total satisfaction of the $i^{\text {th }}$ community \\
\hline$S_{t i}$ & Customer satisfaction with the delivery date \\
\hline$S_{p i}$ & Customer satisfaction with the price of products \\
\hline$S_{d i}$ & Customer satisfaction with the degree of customisation \\
\hline$\omega_{1}, \omega_{2}, \omega_{3}$ & Weights of $S_{t i}, S_{p i}$ and $S_{d i}$ \\
\hline$T_{i}$ & Actual delivery date \\
\hline$T_{\min }$ & Minimum of $T_{i}$ \\
\hline$T_{\max }$ & Maximum of $T_{i}$ \\
\hline$R_{i}$ & Customers' expected degree of product customisation \\
\hline$r_{i}$ & Actual degree of product customisation \\
\hline$S$ & Total satisfaction of communities \\
\hline$q_{\min }$ & Minimum production volume \\
\hline$q_{\max }$ & Maximum production capacity \\
\hline$P_{\max }$ & Highest price that customers are willing to pay \\
\hline$C_{\max }$ & Maximum acceptable investment of the enterprise \\
\hline
\end{tabular}




\section{Genetic Algorithm for Multi-objective Optimisation Mathematical Model of Online Community-based Dynamic Customisation}

GA is a classic but effective algorithm proposed by Holland (1973). It is inspired by the genetic evolution process, including selection, crossover and mutation. The well-known paradigms of the evolutionary algorithms are similar to GA, genetic programming (GP) (Koza 1992), evolutionary strategy (ES) (Fogel 1966) and differential evolution (DE) (Storn and Price 1997). In the 1980s and 1990s, the development of computational complexity theory and the urgent need for industrial application have greatly promoted the research into new search mechanism and optimisation strategies; this has set in motion the research upsurge in heuristic algorithms. For example, there is the simulatedannealing algorithm (SAA) (Kirkpatrick et al. 1983), the tabu search (TS) (Glover 1986) and the backpropagation neural network (BPNN) (McClelland 1986). There are also algorithms in the field of swarm intelligence. Particle-swarm optimisation (PSO) (Eberhart and Kennedy 1995) and ant-colony optimisation (ACO) (Dorigo et al. 1996) are the most well-known. In recent years, a variety of novel heuristic algorithms have been proposed, such as the firefly algorithm (FA) (Yang 2009), the cuckoo search (CS) (Yang 2009), the bat algorithm (BA) (Yang 2010), the artificial-bee-colony algorithm (ABC) (Seeley 2009) and the krill-herd algorithm (KH) (Gandomi and Alavi 2012).

However, the scope of this paper can be understood as proposing an online community-based dynamic customisation model and proving that this model can be practically applied, rather than focusing on different types of algorithms that could be used to calculate an optimal fitness value. Therefore, this study is only interested in finding an appropriate algorithm that is able to work out the mathematical model in a computational study; debating and comparing the results of different types of the algorithms are not within the scope of this paper.

The reasons for preferring GA are indicated here. First, based on the study by Wang et al. (2014), the authors proposed a chaotic krill-herd algorithm (CKH) and tested it on fourteen benchmark problems, comparing the results to those obtained with nine popular algorithms. The results showed that on average, $\mathrm{CKH}$ performed better than other methods and GA is the second-most-effective one even when multiple runs were made. However, as $\mathrm{CKH}$ is an algorithm only recently proposed, it has not been applied and proven effective in many fields. GA as a widely used algorithm in various fields and has been proven effective in solving mathematical models concerning production allocation (Bao et al. 2014, 2016), is more appropriate for working out our proposed model. Second, the crossover and mutation operator of GA provide a new way to capture uncertainties and randomness in the online community-based dynamic customisation model (Cao et al. 2018). Finally, in order to make the calculation simpler and faster, this study normalised the enterprise profit and customer satisfaction, using the maximum weighted sum as the objective of the model. Thus, it is not necessary to use here a non-dominated sorting genetic algorithm (NSGA).

Therefore, GA was chosen in the methodology of this paper. Besides, in order to check the robustness of the results and evaluate the effectiveness of the GA, a novel algorithm, the FA (Gandomi et al. 2011; Yang 2009), was chosen to solve the proposed model as well. A flow chart demonstrating how GA solves the model is shown in Figure 2: 


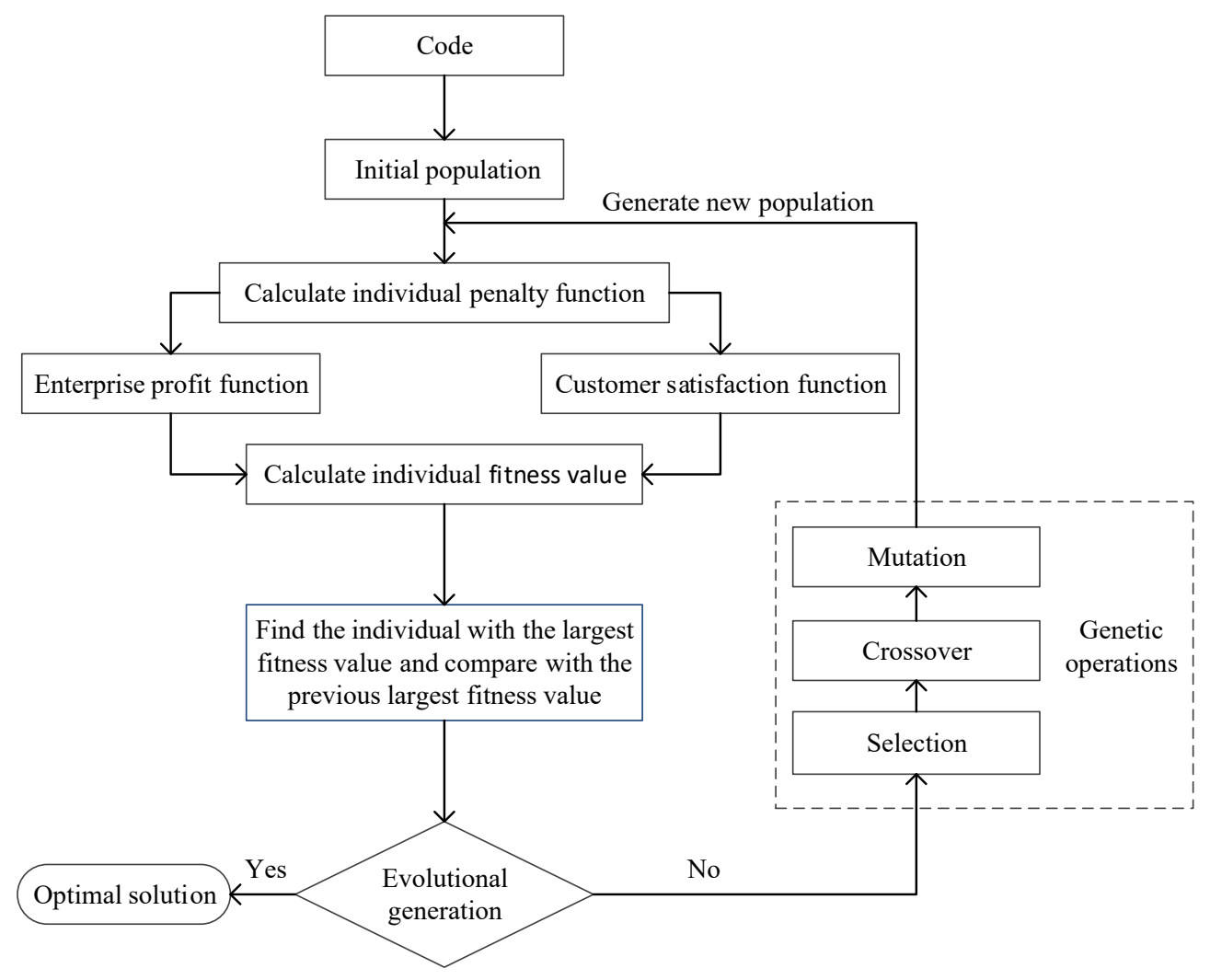

Figure 2. Genetic algorithm flowchart.

\section{(1) Coding and decoding strategy}

This paper uses the decimal-integer coding method to encode the community dynamic customisation model, shown in Figure 3. According to this method, the length of each chromosome is the same as the number of genes, represented as $m$. Each gene represents the price of the product for the $i^{\text {th }}$ OCC, so that the value of $m$ is equal to the number of OCCs. Additionally, each chromosome in the model represents a set of dynamic customised product-manufacturing and -pricing schemes under the constraint of an enterprise. In the optimisation process, the $N \times m$ integer matrix is the initial population to search to determine the optimal solution.

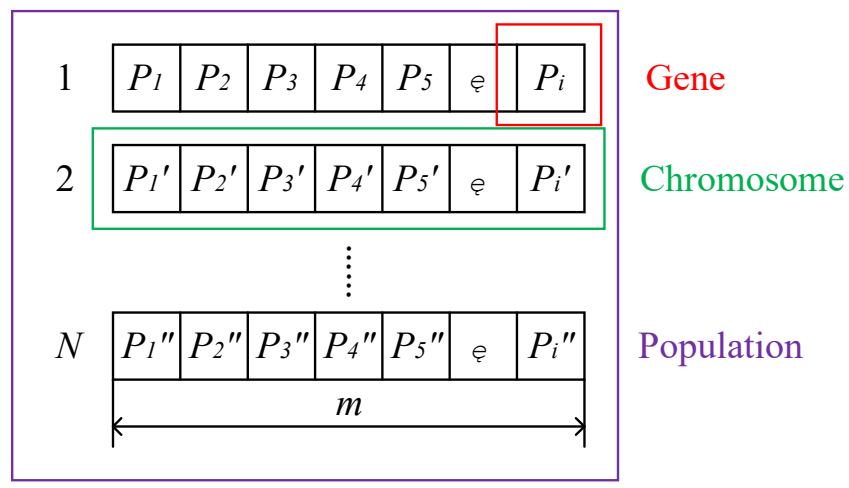

Figure 3. Coding and decoding strategy. 


\section{(2) Design of the fitness function}

As searching in GA is mainly based on the individual fitness value, the selection of fitness function affects both the convergence speed and search efficiency of the GA, such that the design of the fitness function is critical (Bao et al. 2016). To achieve the objective of the proposed mathematical model above, the fitness function is set according to the objective equation (19) as follows:

$$
F=a \times Q+b \times S
$$

\section{(3) Selecting operation}

The selecting operation is completed by the random-number method. This method first converts each fitness function into a value ranging from 0 to 1 . Next, the value ahead is compared to the value, from 0 to 1 that is randomly generated to select the individuals with good genes as offspring. Each individual can only be chosen once. In this study, 50 individuals were selected as offspring. The fitness function $F$ was normalised as follows:

$$
F^{\prime}=\frac{F-F_{\min }}{F_{\max }-F_{\min }}
$$

\section{(4) Adaptive crossover and mutation operation}

This study used two-point crossover and two-point mutation, shown in Figures 4 and 5. In the crossover operation, two chromosomes are randomly selected and cut into four pieces (with different colours in Figure 4) in the same positions of the chromosomes randomly. The second and fourth pieces of these two chromosomes then exchange with each other. In the mutation operation, two genes of a chromosomes are randomly selected and mutate into other pieces. The chromosomes are recombined and inherited, generating new offspring with a crossover probability of 0.9 and a mutation probability of 0.05 (assumptions).

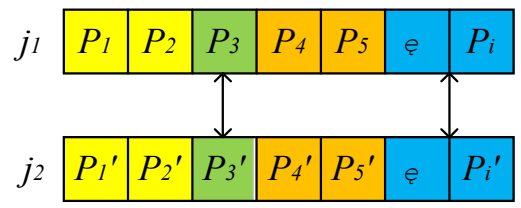

Figure 4. Crossover operation.

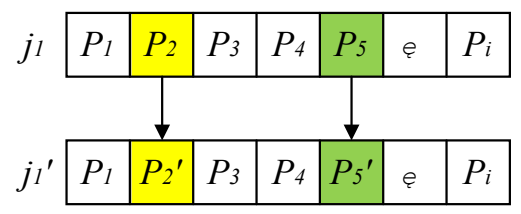

Figure 5. Mutation operation.

\section{(5) Terminate the algorithm}

As it is difficult to predict the optimal solution of the model in advance, the evolutional generation (EG) of the algorithm is set to 500 times as a termination signal. 


\section{Computational Study}

This section deploys a case study of an enterprise that provides customised menswear to test and validate the proposed model and algorithm. Section 6.1 introduces the basic information of the case enterprise and the simulated parameters and data needed for the model. Three scenarios, including maintaining the present customisation degree, additive customisation and subtractive customisation, are solved and compared in Section 6.2. Section 6.3 analyses the sensitivity of the weights of the enterprise-profit function and the customer-satisfaction function to assess the impact of the functions' weights on the results of the model. Finally, a novel algorithm, the firefly algorithm (FA), is used to solve the proposed model again to check the robustness of the results and evaluate the effectiveness of GA (see Section 6.4).

Case-based research seeks to find logical connections among observed events, relying on knowledge of how systems, organisations and individuals function (Kaplan and Duchon 1988; McCutcheon and Meredith 1993). The model developed in this study was applied to one case enterprise to understand the 'how' and 'why' of the model's performance (McCutcheon and Meredith 1993; Yin 2003). Only one case enterprise was used because applying the model requires not only the availability of an enterprise's data but also a considerable amount of its time and resources. The study of a limited number of case applications permitted a more detailed assessment of the model's performance.

\subsection{The basic parameters of the case study}

An enterprise that provides customised menswear with an online customisation platform was used as a case study to illustrate and test the proposed model and algorithm. This enterprise has total assets of 1.2 billion yuan, with annual sales revenue of nearly 1 billion yuan. The enterprise sells customised clothes both in store and online. It has more than 5,000 specialist employees and an annual production capacity of 800,000 suits, 6 million shirts and 10 million pairs of pants. The enterprise also has a professional Lectra computer-aided design (CAD) and Computer-aided manufacturing (CAM) system to provide technical support for personalisation purposes. Overall, the enterprise is one of the most successful customised apparel enterprises in China.

In the configuration system of the enterprise, shown in Figure 6, customers can independently personalise their clothes and order them. Meanwhile, the enterprise is able to collect the customers' information and order details to better match the customers' demand with the enterprise's supply in time. Considering the constraints of customers and enterprises, this study can assist the enterprise in investigating the optimal pricing portfolio for its customised products, as well as the optimal matching mode with manufacturers. This could help the enterprise achieve an optimal dynamic trade-off between customer satisfaction and enterprise profit. First, based on the actual context of this customised menswear customised, the following four sections identify and outline the parameters and data needed for the model. 


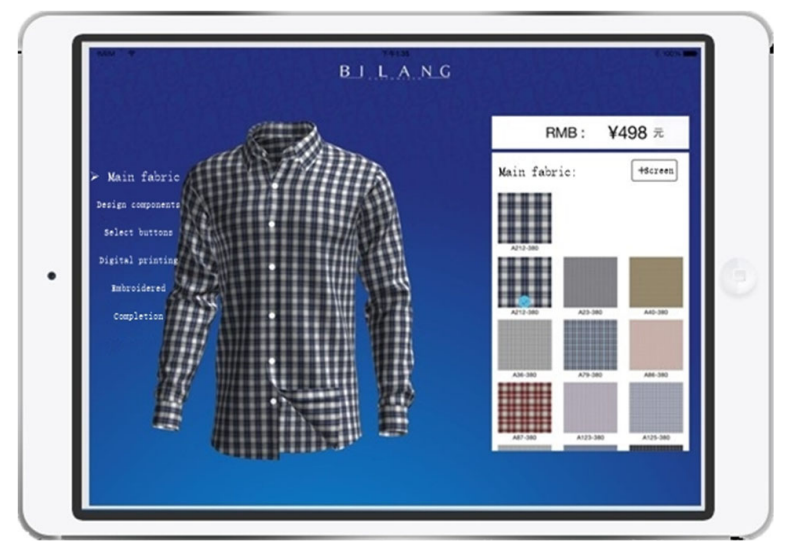

Figure 6. The configuration system of the case enterprise.

\section{(1) Weights of the three dimensions of customer satisfaction}

The weights of the three dimensions of customer satisfaction were determined by a questionnaire, which focused on males aged 20 to 50 from China. Respondents' ages were further divided into two age groups - one for young adults aged 20 to 35, and the other for middle-aged adults aged 36 to 50 . To measure the importance of each dimension to the respondents, a total of 100 points was allocated to all three dimensions. The percentage of points in each dimension was measured as the weight of each dimension of customer satisfaction. The questionnaire's three dimensions and results are shown in Table 4(a).

By arithmetical average, the weights of the three dimensions of customer satisfaction were calculated using $\omega=[0.25,0.284,0.465]^{T}$.

\section{(2) Weights of the enterprise-profit and customer-satisfaction functions}

The weights of the enterprise-profit and customer-satisfaction functions are influenced by the development stage of the enterprise, as well as by manager preferences. Thus, based on decisions made by experts working in the customised menswear enterprise (each expert was given 100 points to distribute between enterprise profit and customer satisfaction), the weights of enterprise profit and customer satisfaction were set as $a=0.3$ and $b=0.7$, respectively.

\section{(3) Basic situation of the community}

Based on the number of customised product attributes, the target customers were divided into seven communities. After processing the data, the basic situation of each community is listed in Table 4(b).

\section{(4) Basic situation of the enterprise}

Based on the data provided by the customised menswear enterprise, the properly processed production data is included in Table 4(c).

Additionally, the cost of truck transportation is based on different cooperation modes between the enterprise and manufacturers. Obviously, a truck must drive between the enterprise and manufacturers 
at least twice, and transportation distances for different communities in different cooperation modes vary. This data was calculated based on the data in Table 4(b) and (c), and the results are shown in Table 4(d).

Based on the acceptable customisation degree for the enterprise in Table 4(c), the enterprise can only meet the customisation expectations of communities A to D, such that the cost of transportation for communities $\mathrm{E}, \mathrm{F}$ and $\mathrm{G}$ should be the same as that of community $\mathrm{D}$. 
Table 4. The case study parameters and data for the mathematical model

(a) Results of the average weight of the three dimensions of customer satisfaction

\begin{tabular}{lccc}
\hline \multicolumn{1}{c}{ Dimension } & Delivery date & Price & Customisation level \\
Age group & & & \\
\hline Young adults & 0.22 & 0.35 & 0.43 \\
Middle-aged & 0.28 & 0.22 & 0.5 \\
\hline
\end{tabular}

(b) Basic information of each OCC of the case enterprise

\begin{tabular}{cccccccc}
\hline Community & A & B & C & D & E & F & G \\
\hline Customisation degree $\left(R_{i}\right)$ & 1 & 2 & 3 & 4 & 5 & 6 & 7 \\
Minimum intolerance $\left(d_{i}\right)$ & 3 & 3 & 3 & 3 & 3 & 3 & 3 \\
Acceptable maximum delivery $\left(T_{\text {max }} /\right.$ day $)$ & 10 & 10 & 10 & 10 & 10 & 10 & 10 \\
Maximum demand $\left(\gamma_{i}\right)$ & 5900 & 6200 & 7000 & 7900 & 8500 & 9200 & 10000 \\
Price-sensitive coefficient $\left(\beta_{1}\right)$ & 1.55 & 1.35 & 1.15 & 0.95 & 0.88 & 0.8 & 0.7 \\
Delivery-sensitive coefficient $\left(\beta_{2}\right)$ & 1.4 & 1 & 0.9 & 0.7 & 0.68 & 0.68 & 0.67 \\
\hline
\end{tabular}

(c) Production data of the case enterprise

\begin{tabular}{cccccccc}
\hline Community & A & B & C & D & E & F & G \\
\hline Actual delivery $\left(T_{i} /\right.$ day $)$ & 0.25 & 1.6 & 2.95 & 4.3 & 5.65 & 7 & 7 \\
Acceptable customisation degree for the enterprise $\left(r_{i}\right)$ & 1 & 2 & 3 & 4 & 4 & 4 & 4 \\
Production cost for a single product $(v /$ yuan $)$ & 30 & 30 & 30 & 30 & 30 & 30 & 30 \\
Operation cost for a single product $(\alpha /$ yuan $)$ & 10 & 10 & 10 & 10 & 10 & 10 & 10 \\
Minimum delivery date $\left(T_{\min } /\right.$ day $)$ & 0.25 & 0.25 & 0.25 & 0.25 & 0.25 & 0.25 & 0.25 \\
Maximum customisation level $\left(r_{\max }\right)$ & 4 & 4 & 4 & 4 & 4 & 4 & 4 \\
Cost for single shipping $(\theta /$ yuan $)$ & 500 & 500 & 500 & 500 & 500 & 500 & 500 \\
Cost for single delivery $(\phi /$ yuan $)$ & 3 & 3 & 3 & 3 & 3 & 3 & 3 \\
Maximum investment for the enterprise $\left(C_{\text {max }} /\right.$ yuan $)$ & & & & 7000000 & & & \\
Warehousing cost $\left(C_{d c i} /\right.$ yuan $)$ & & & & 5000 & & & \\
\hline
\end{tabular}


(d) Transportation distances for each community in different cooperation modes of the case enterprise

\begin{tabular}{c|ccccccc}
\hline & Community & B & C & D & E & F & G \\
\hline Many-to-one & & & & & & & \\
Many-to-many & 1 & 1 & 1 & 1 & 1 & 1 & 1 \\
One-to-one & 2 & 3 & 4 & 5 & 5 & 5 & 5 \\
& 2 & 2 & 2 & 2 & 2 & 2 & 2 \\
\hline
\end{tabular}

\subsection{Proposed scenarios}

The customisation strategies regarding the customisation degree for the enterprise include maintaining its present status, additive customisation ${ }^{1}$ and subtractive customisation. ${ }^{2}$ Section 6.2.1 solves and analyses the trade-off of online community-based customisation while maintaining the present customisation degree; Section 6.2.2 focuses on comparing the results of additive and subtractive customisation.

In the strategy that maintains the present assumptions, the number of designable attributes is expressed as the maximum degree of customisation $\left(r_{\text {max }}\right)$ that can be satisfied by the enterprise. While the number of selectable attributes is positively correlated with the maximum demand $\left(\gamma_{i}\right)$ of each community. When there are more styles that can be selected during customisation, more customers will customise products, as the enterprise can better satisfy their demand. Thus, based on the additive and subtractive customisation, the function of the model is processed as follows:

$$
\begin{gathered}
r_{\text {max }}{ }^{\prime}=r_{\text {max }}+1 \\
\gamma_{i}^{\prime}=\gamma_{i}+500 \\
r_{\text {max }}{ }^{\prime \prime}=r_{\text {max }}-1 \\
\gamma_{i}{ }^{\prime}=\gamma_{i}-500
\end{gathered}
$$

where expressions (26) and (27) represent additive customisation, and expressions (28) and (29) represent subtractive customisation.

\subsubsection{Scenario 1: The strategy of maintaining the present customisation degree}

The results of the online community-based dynamic customisation model in the three cooperation modes were derived from MATLAB R2016b, shown in Figure 7:

${ }^{1}$ Additive customisation means providing more designable or selectable attributes for customers to customise. ${ }^{2}$ Subtractive customisation means providing fewer designable or selectable attributes for customers to customise. 


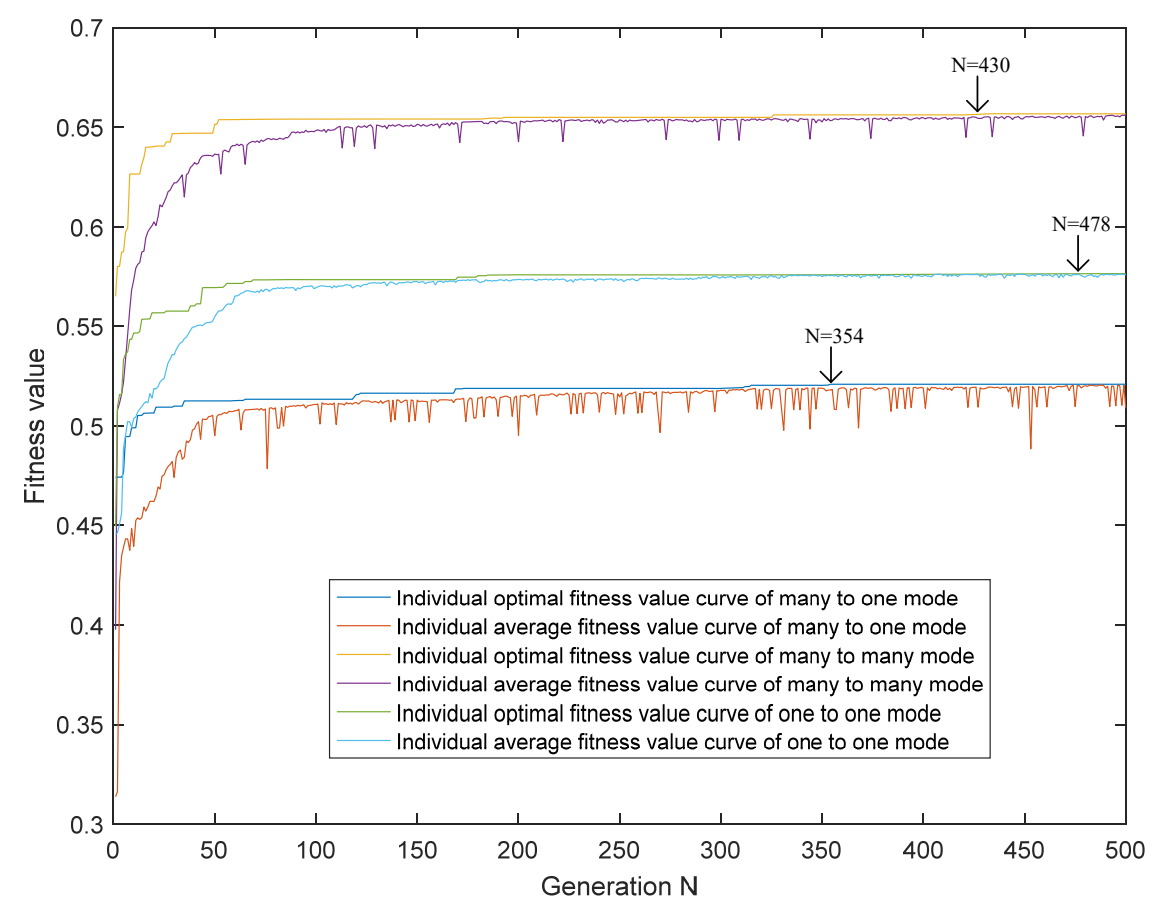

Figure 7. Computational results of maintaining the present customisation degree.

As seen in Figure 7, the model was iterated 500 times in in each of the three cooperation modes. There are two kinds of individual fitness value curves. The individual average fitness value curves and the individual optimal fitness value curves describe the mean and maximum of the individual fitness value of each generation, respectively. The locations where the optimal solution occurs (the number of iterations) are indicated in Figure 7. If these two kinds of curves have similar tendencies, the convergence effect is satisfying. Thus, the convergence effect was satisfying in scenario 1 . The results showed that the optimal fitness value $(F)$ were $0.5209,0.6568$ and 0.5765 in the many-to-one mode, many-to-many mode and one-to-one mode, respectively. The fitness value of the many-to-many mode was the highest. Therefore, in short, only the many-to-many mode was further assessed; the detailed results of which are shown in Table 5.

Table 5. The trade-off of online community-based customisation of many-to-many mode

\begin{tabular}{cccccccccc}
\hline Community & Total & A & B & C & D & E & F & G \\
\hline Price of community $i\left(P_{i}\right)$ & & 169.6 & 441.0 & 1564.1 & 2896.3 & 3942.5 & 5188.7 & 7092.1 \\
Satisfaction of community $i\left(S_{i}\right)$ & 0.5696 & 0.9210 & 0.8120 & 0.6454 & 0.5730 & 0.5151 & 0.3694 & 0.0793 \\
Profit of community $i\left(Q_{i}{ }^{\prime}\right)$ & 0.8602 & 0.0004 & 0.0092 & 0.0570 & 0.1111 & 0.1598 & 0.2178 & 0.3048 \\
\hline
\end{tabular}

Clearly the price of customised products increased with a higher degree of customisation. As concluded by Dewan (2000), customisation cost is positively correlated with customisation scope. 
Additionally, the results of the model are in accordance with the actual situation. Therefore, our multiobjective optimisation mathematical model of online community-based dynamic customisation is feasible. Through optimisation, the combination of enterprise profits and OCC satisfaction reached an optimised situation with values of more than 0.5 .

However, the enterprise's maximum customisation level, $r_{\text {max }}$, was 4, which cannot satisfy the demand of communities E, F and G. The products for these communities are the same as those for community D. Thus, the prices of the products for these communities should be the same as those for community D.

To address the challenge mentioned above, there are two possible solutions: one is taking the average price of communities D, E, F and G as the common final price; while the other is taking the price of community $\mathrm{D}$ as the common final price.

After calculation, the optimal fitness value $(F)$ of the first solution was 0.6325 , while the optimal fitness value $(F)$ of the second solution was 0.5707 . The detailed results are shown in Table 6 .

Table 6. The results of the two solutions

\begin{tabular}{cccccccccc}
\hline Solution & Community & Total & A & B & C & D & E & F & G \\
\hline \multirow{2}{*}{$\begin{array}{c}\text { First } \\
\text { solution }\end{array}$} & $P_{i}$ (yuan) & & 169.6 & 441.0 & 1564.1 & 4779.9 & 4779.9 & 4779.9 & 4779.9 \\
& $S_{i}$ & 0.5466 & 0.9209 & 0.8120 & 0.6454 & 0.5570 & 0.5095 & 0.3715 & 0.0890 \\
& $Q_{i}{ }^{\prime}$ & 0.8328 & 0.0004 & 0.0092 & 0.0570 & 0.1226 & 0.1691 & 0.2119 & 0.2626 \\
\hline \multirow{2}{*}{$\begin{array}{c}\text { Second } \\
\text { solution }\end{array}$} & $P_{i}$ (yuan) & & 169.6 & 441 & 1564.1 & 2896.3 & 2896.3 & 2896.3 & 2896.3 \\
& $S_{i}$ & 0.5405 & 0.9209 & 0.8120 & 0.6454 & 0.5730 & 0.5312 & 0.3977 & 0.1220 \\
& $Q_{i}{ }^{\prime}$ & 0.6411 & 0.0004 & 0.0092 & 0.0570 & 0.1111 & 0.1324 & 0.1532 & 0.1777 \\
\hline
\end{tabular}

According to the results, the values of total customer satisfaction and enterprise profit in the first solution are both larger than those in the second solution. Thus, the first solution is more suitable for pricing the products for communities E, F and G. Therefore, when the enterprise chooses the manyto-many mode and the pricing portfolio [169.6, 441.0, 1564.1, 4779.9, 4779.9, 4779.9, 4779.9] for communities $A$ to $G$, it can achieve the maximum combination of enterprise profit and customer satisfaction.

The computational study described above confirms the existence of a community economy in production, which was previously observed by Manchanda (2015). Moreover, the results for customer satisfaction and enterprise profit demonstrate that an enterprises that provide customised products can profit from its customers, which was also previously reported by Georgescu (2005).

\subsubsection{Scenarios 2 and 3: Additive customisation and subtractive customisation}

After determining the trade-off of online community-based dynamic customisation with the present customisation degree, the additive customisation and subtractive customisation strategies were 
analysed to determine which strategy generated higher enterprise profit and customer satisfaction. The results of the additive customisation and subtractive customisation strategies are shown in Figure 8.

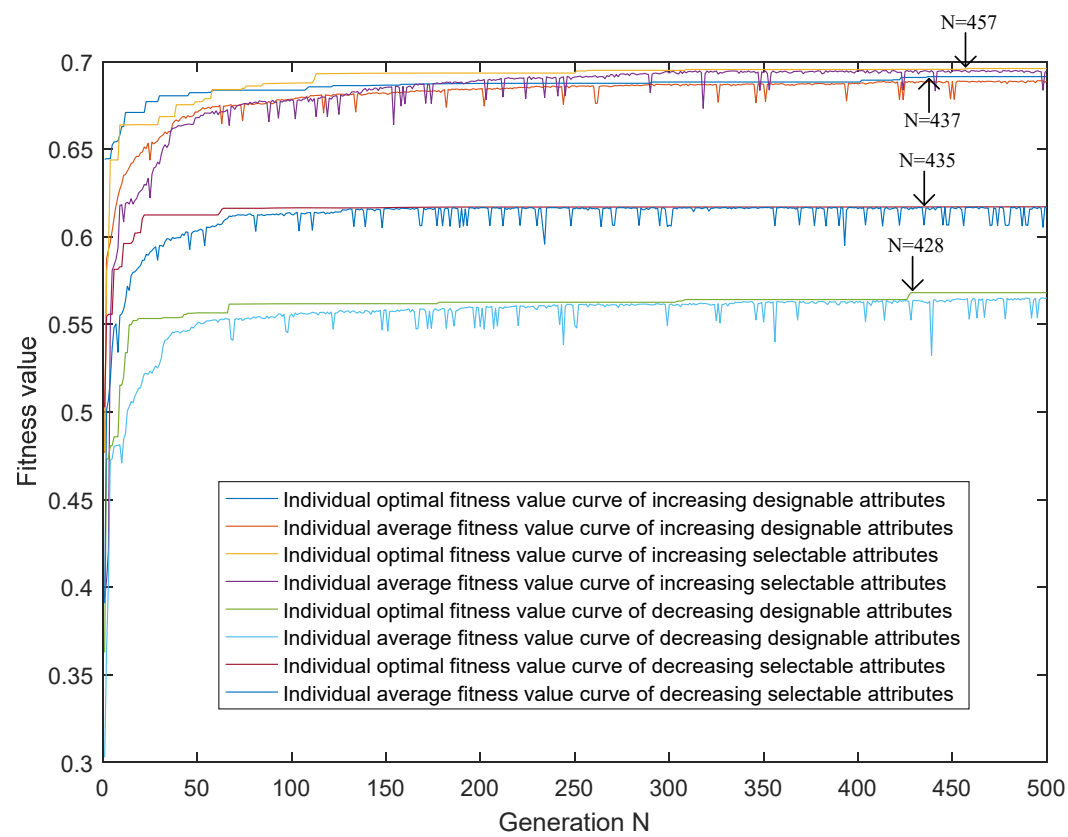

Figure 8. Computational results of the additive customisation and subtractive customisation strategies.

As seen in Figure 8, the optimisation process had a good convergence effect, and the locations at which the optimal solution occurs (the number of iterations) are indicated in Figure 8. In the additive customisation, the optimal fitness value $(F)$ was 0.6915 when the number of designable attributes increased. The optimal fitness value $(F)$ was 0.6960 when the number of selectable attributes increased. In the subtractive customisation, the optimal fitness value $(F)$ was 0.5680 when the number of designable attributes decreased. The optimal fitness value $(F)$ was 0.6171 when the number of selectable attributes decreased. Therefore, under the implementation of the additive customisation 